\title{
Assessment of Groundwater Vulnerability to Pollution Using VLDA and COP Models in Halabja Saidsadiq
}

\section{Iraq}

\author{
Twana O. Abdullah ${ }^{1,2}$, Salahalddin S. Ali ${ }^{3,4}$, Nadhir A. Al-Ansari ${ }^{2}$ and Sven Knutsson ${ }^{2}$ \\ 1. Groundwater Directorate of Sulaimani, Kurdistan Region, NE 46001, Iraq \\ 2. Department of Civil, Environmental and Natural Resources and Engineering, Division of Mining and Geotechnical Engineering, \\ Lulea University of Technology, Lulea 971 87, Sweden \\ 3. Department of Geology, University of Sulaimani, Kurdistan Region, NE 46001, Iraq \\ 4. Komar University of Science and Technology, Sulaimani, Iraqi Kurdistan Region, 46001, Iraq
}

\begin{abstract}
Groundwater aquifer in the HSB (Halabja and Saidsadiq Basin) is considered being one of the most important aquifers in terms of water supplying in Kurdistan Region, NE of Iraq. The growing of economics, irrigation and agricultural activities inside the basin makes it of the main essentials to the region. Therefore, pollution of groundwater is of specific worry as groundwater resources are the principal source of water for drinking, agriculture, irrigation and industrial activities. Thus, the best and practical arrangement is to keep the pollution of groundwater through. The current study aims at the evaluation of the vulnerability of groundwater aquifers of the study area. Two models were applied, to be specific VLDA and COP to develop maps of groundwater vulnerability for contamination. The VLDA model classified the area into four classes of vulnerability with each covered area: low (2\%), moderate (44\%), high (53\%) and very high (1\%). While four vulnerability classes were accomplished dependent on COP model including very low, low, moderate and high vulnerability classes with coverage areas of $1 \%, 37 \%, 2 \%$ and $60 \%$ respectively. To confirm the suitability of each map for assessment of groundwater vulnerability in the area, it required to be validated of the theoretical sympathetic of current hydrogeological conditions. In this study, groundwater age evaluated utilizing tritium isotopes investigation and applied it to validate the vulnerability results. Based on this validation, the outcome exhibits that the vulnerability classes acquired utilizing VLDA model are more predictable contrasted with the COP model.
\end{abstract}

Key words: Vulnerability, VLDA, COP, HSB.

\section{Introduction}

HSB (Halabja and Saidsadiq Basin) is considered to be one of the most important basins in Kurdistan Region, NE of Iraq, in terms of groundwater aquifers. The concentration of economic, agricultural and social activities within the basin makes it of prime significance to the region. Exhaustive agricultural activities are extensive and located close to groundwater wells, which pose imminent threats to these resources. Moreover, the authoritative structure of Halabja has been changed from a district to

Corresponding author: Nadhir A. Al-Ansari, professor, research fields: water resources and environment. governorate in March 2014; this will improve the start of more economic improvement and progression. In perspective of these progressions, there is an expansion of the quantities of human making a beeline for live in this basin and its surrounding areas. This is forcing a developing interest in water which has set significant weights on water resources. Therefore, groundwater contamination is of particular concern as groundwater resources are the principal source of water for drinking, agriculture, irrigation and industrial activities.

Groundwater vulnerability is evaluating the ability of pollutant to transport from the earth surface to reach a productive aquifer. The vulnerability studies 
can supply precious information about stakeholder working on preventing further deterioration of the environment [1]. To simplify the identification of the groundwater condition and to resist the pollutants in the reservoirs, several methods were recommended such as DRASTIC, VLDA, COP, GOD, SINTACS, etc. These different methods are offered under the form of numerical excerpt systems based on the negotiation of the different factors affecting the hydrogeological system [2].

Different vulnerability models were applied previously for the studied area; while it is very important to confirm the computed vulnerability model is reflecting the real vulnerability system for the area. So the main objective of the current study is to compare the achieved vulnerability map from two different models namely VLDA and COP, in order to select more sensible model to be applied for the area.

\subsection{Study Area}

The study basin is located in the northeastern part of Iraq, geographically it is located between the latitude $35^{\circ} 00^{\prime} 00^{\prime \prime}$ and $35^{\circ} 36^{\prime} 00^{\prime \prime} \mathrm{N}$ and the longitude $45^{\circ} 36^{\prime} 00^{\prime \prime}$ and $46^{\circ} 12^{\prime} 00^{\prime \prime} \mathrm{E}$ (Fig. 1). The entire study area is about 1,278 square kilometers and its population of early 2015 of about 190,727. This basin is divided into two sub-basins by Ali [3] including Halabja-Khurmal and Said Sadiq sub-basins. Approximately $57 \%$ of the studied area is an arable area due to its suitability for agriculture [4].

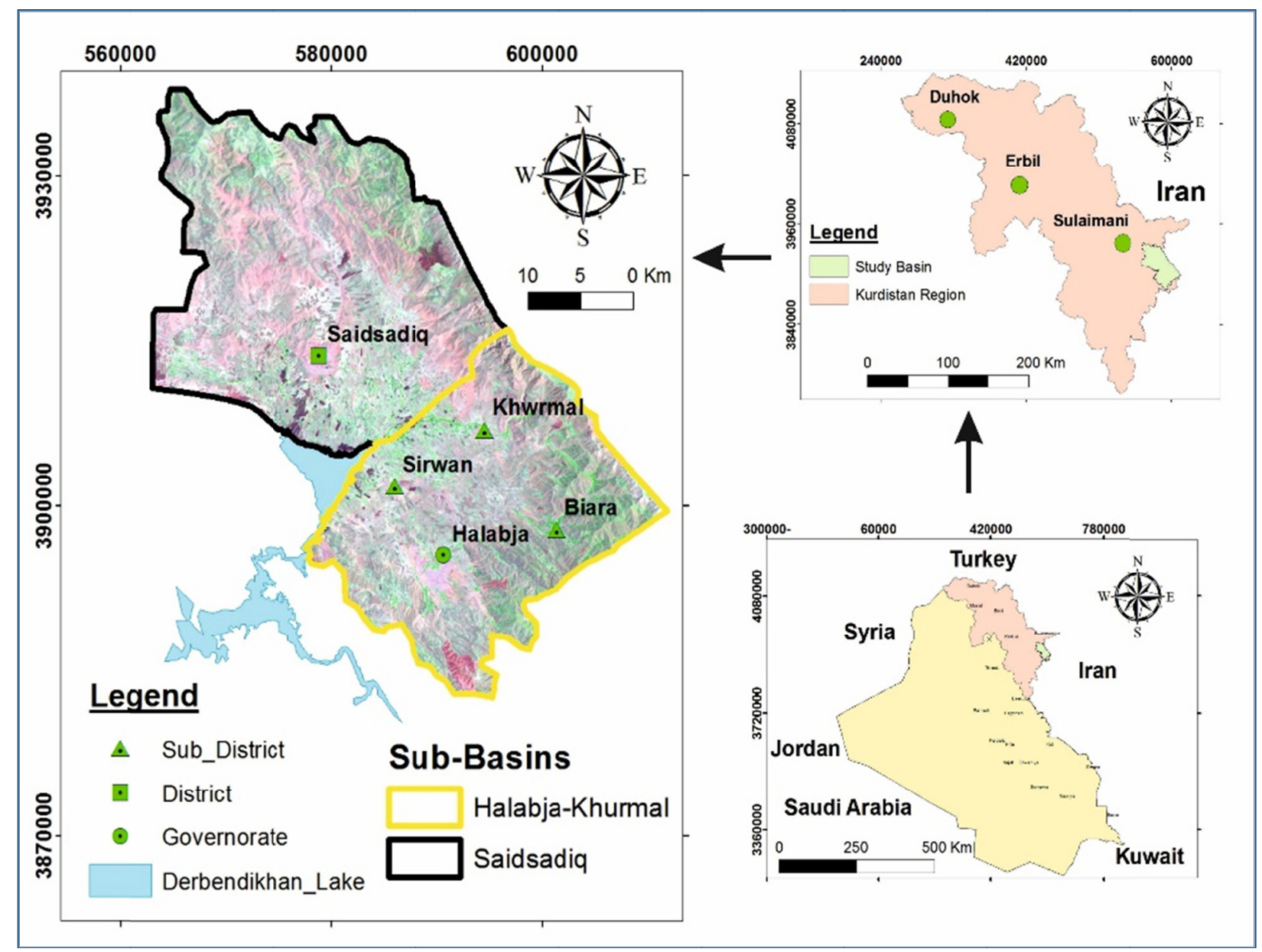

Fig. 1 Location map of study basin. 


\subsection{Geology and Hydrogeological Setting}

Different geological formations were exposed to the basin, these formations consist of limestone, dolomitic limestone and conglomerate which have an effective role in the vulnerability system in the basin (Fig. 2). Alluvial (quaternary) deposits are the most important unit in the area in terms of hydrogeological characteristics and water supply. The thickness of these deposits as observed by Abdullah et al. [5] is about nearly $300 \mathrm{~m}$.
Hydrogeologically, different groundwater aquifers exist in the area based on its geological origin, as shown in Table 1 and Fig. 3. The mountain series, which surround the basin of the northeast and southeast, are characterized by high depth of groundwater, while toward the center and the southeastern part, the groundwater level has a relatively lower depth. A groundwater movement is usually from high elevated areas at the north, northeast, south and southeast towards southwest or generally toward the reservoir of Derbandikhan Dam.

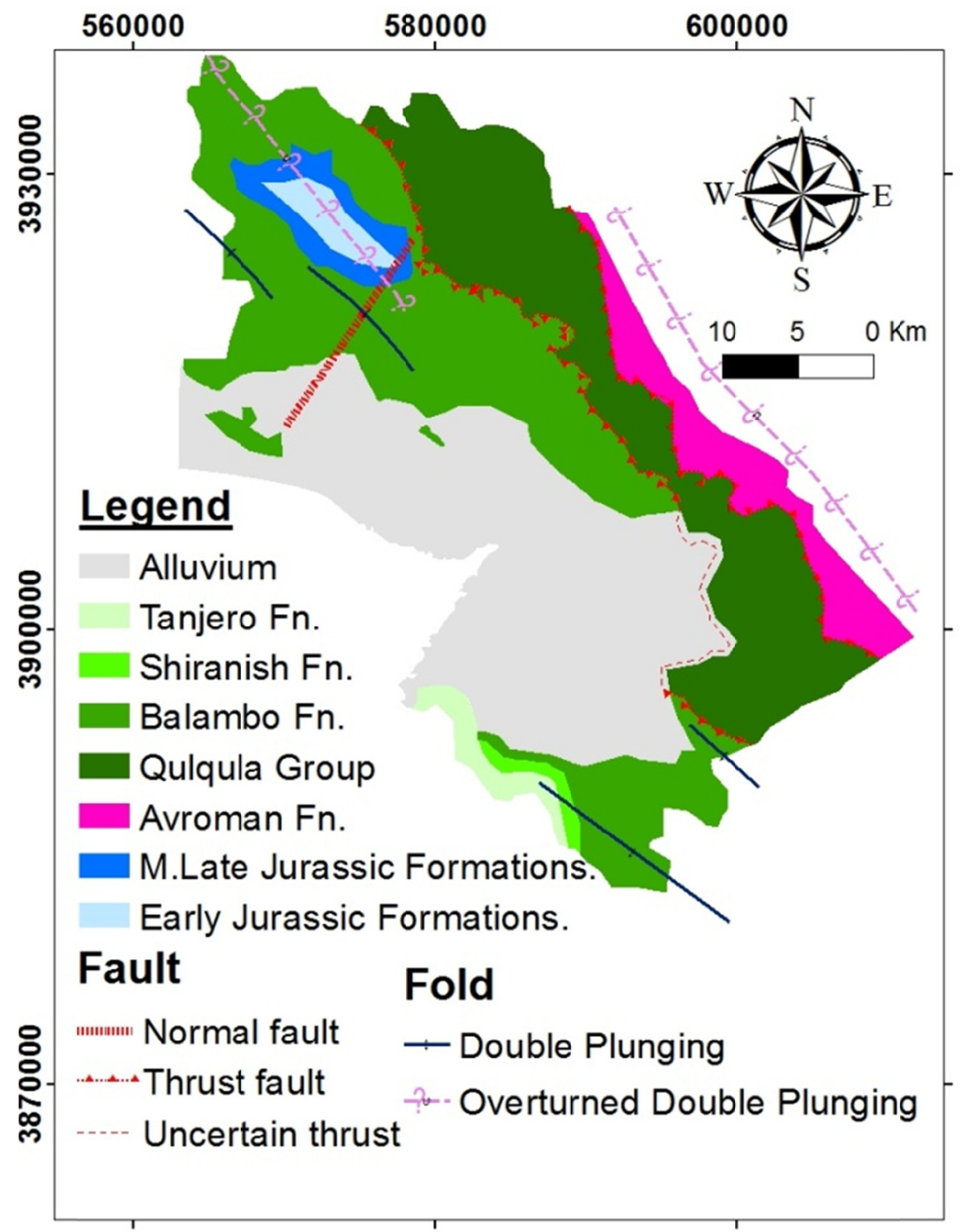

Fig. 2 Geological map of the HSB (modified from Abdullah et al. [5]). 
Table 1 Type of aquifers in the study basin.

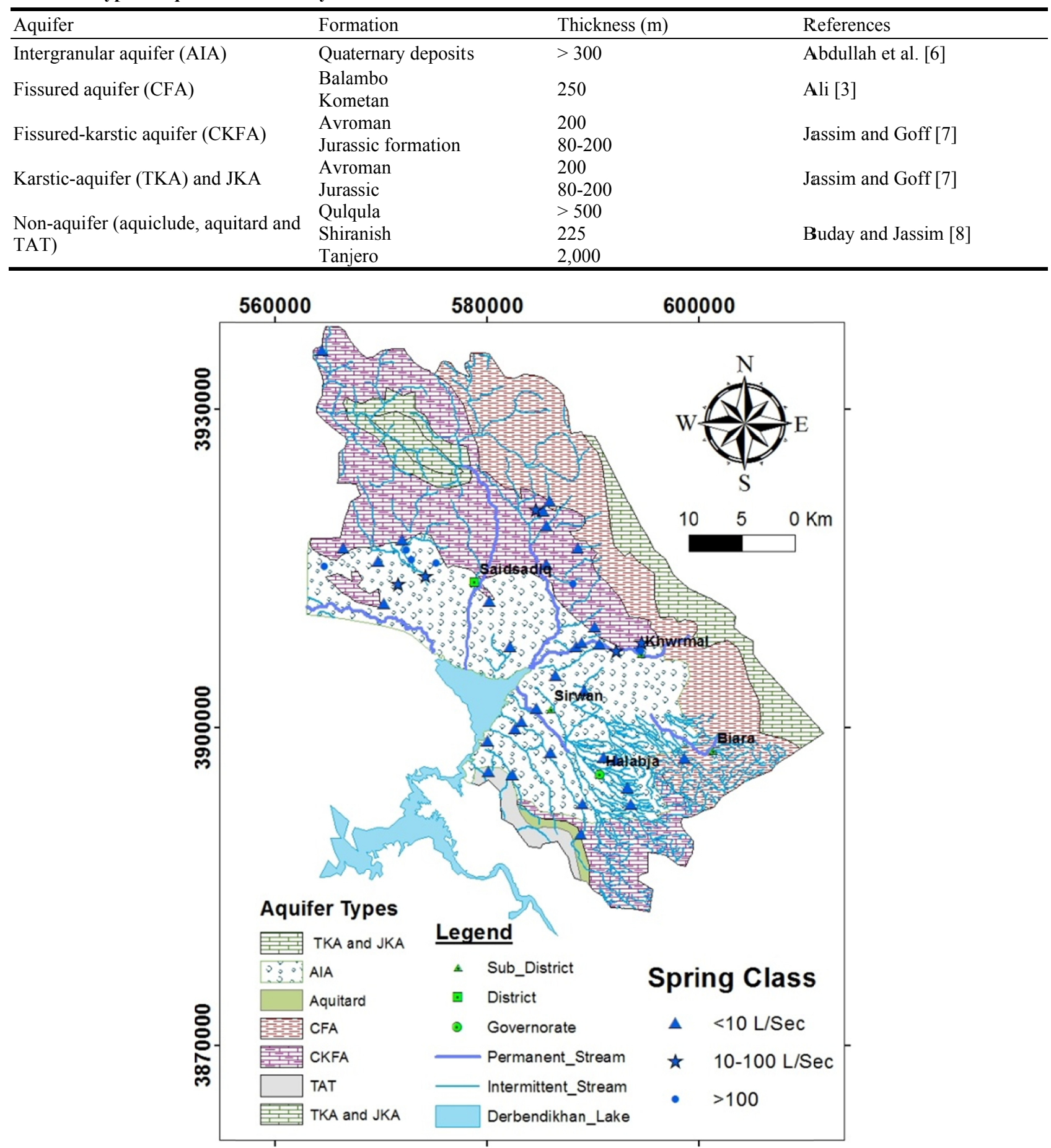

Fig. 3 Hydrogeological map of the HSB (modified from Abdullah et al. [5]). 


\section{Methodology}

Two different models have been applied with the aid of GIS technique in order to map groundwater vulnerability in the study area. The first applied model is VLDA, predominantly it reflects lithology of vadose zone $(\mathrm{V})$, pattern of land use $(\mathrm{L})$, groundwater depth (D), and aquifer characteristics (A) [9]. In addition, reliable weight can be assigned to each of the four indexes depending on its impact on groundwater vulnerability.

The vulnerability comprehensive assessment index $(D I)$ is the sum of the above-mentioned weighted four indexes, as computed conferring to the following formula:

$$
D I=\sum_{j=1}^{4}(\mathrm{Wij} R \mathrm{ij})
$$

where, $D I$ is the comprehensive assessment index, $W i j$ is the weight of the $j^{\text {th }}$ comprehensive assessment index of the $i^{\text {th }}$ sub-system, $R i j$ is the value of the $j^{\text {th }}$ assessment index of the $i^{\text {th }}$ subsystem; 4 is the quantity of indexes.

The lower the $D I$ signifier to the lower vulnerability of the groundwater system and the superior the stability will be. To assess the groundwater vulnerability, the new corresponding weights in HSB were proposed using sensitivity analysis method [6]. Based on the result of sensitivity analysis, the proposed weights used for VLDA model measured as 8.2, 4.8, 5.2 and 4.8 , and after normalization, the weight is $0.357,0.209,0.226$ and 0.209 , respectively [10].

The second applied model is COP; its contraction comes from the three initials of parameters namely flow Concentration (C), Overly layers (O) and Precipitation (P) [11]. The hypothetical basis of this strategy, as indicated by the European Approach [12, 13], it is to evaluate the ordinary protection for groundwater ( $\mathrm{O}$ variable) controlled by the properties of overly soils and the unsaturated zone, and also to measure how this assurance can be adjusted by diffuse, infiltration $(\mathrm{C}$ factor) and the climatic conditions $(\mathrm{P}$ Factor - precipitation). The COP-index map was computed from Eq. (2) [11]:

$$
\text { COP Index Map }=C^{*} O^{*} P \quad \text { (2) [14] }
$$

\section{Result and Conclusions}

Subsequent to the weighted scores were achieved for all parameters in each model, the GIS technique was used to combine all layers. The vulnerability result based on VLDA model, illustrates that a total of four ranges of vulnerability indexes had been distinguished ranging from low on very high, with vulnerability indexes $(2.133-4,>4-6,>6-8$ and $>8)$ as shown in Fig. 4. The areas of low and very high vulnerability zones occupy $2 \%$ and $1 \%$ of the whole study area respectively. The high vulnerability classes covered most of the mountains area that surrounding the area of study and the central part of HSB. This vulnerability zone covered an area of $53 \%$ of whole area. Furthermore, medium vulnerability zones covered an area of $44 \%$ of all studied area and positioned southeast and northwest. Both high and moderate classes that occupied most of the studied basins refer to the exhaustive human activities, good water yield property and lithological composition of existed aquifers.

Four categories of vulnerability ranging from very low to high are achieved according to the COP model (Fig. 5). High vulnerability areas covering an area of $60 \%$ of the entire HSB, geologically include the fissure zone and minor carbonate karstic rocks. While the low vulnerability class comes in second place and occupies $37 \%$ of the entire region, this region is predominantly characterized by alluvial sediments. The area with moderate and very low vulnerable groups covers only $2 \%$ and $1 \%$ of the total area, respectively. 

Saidsadiq Basin, Iraq

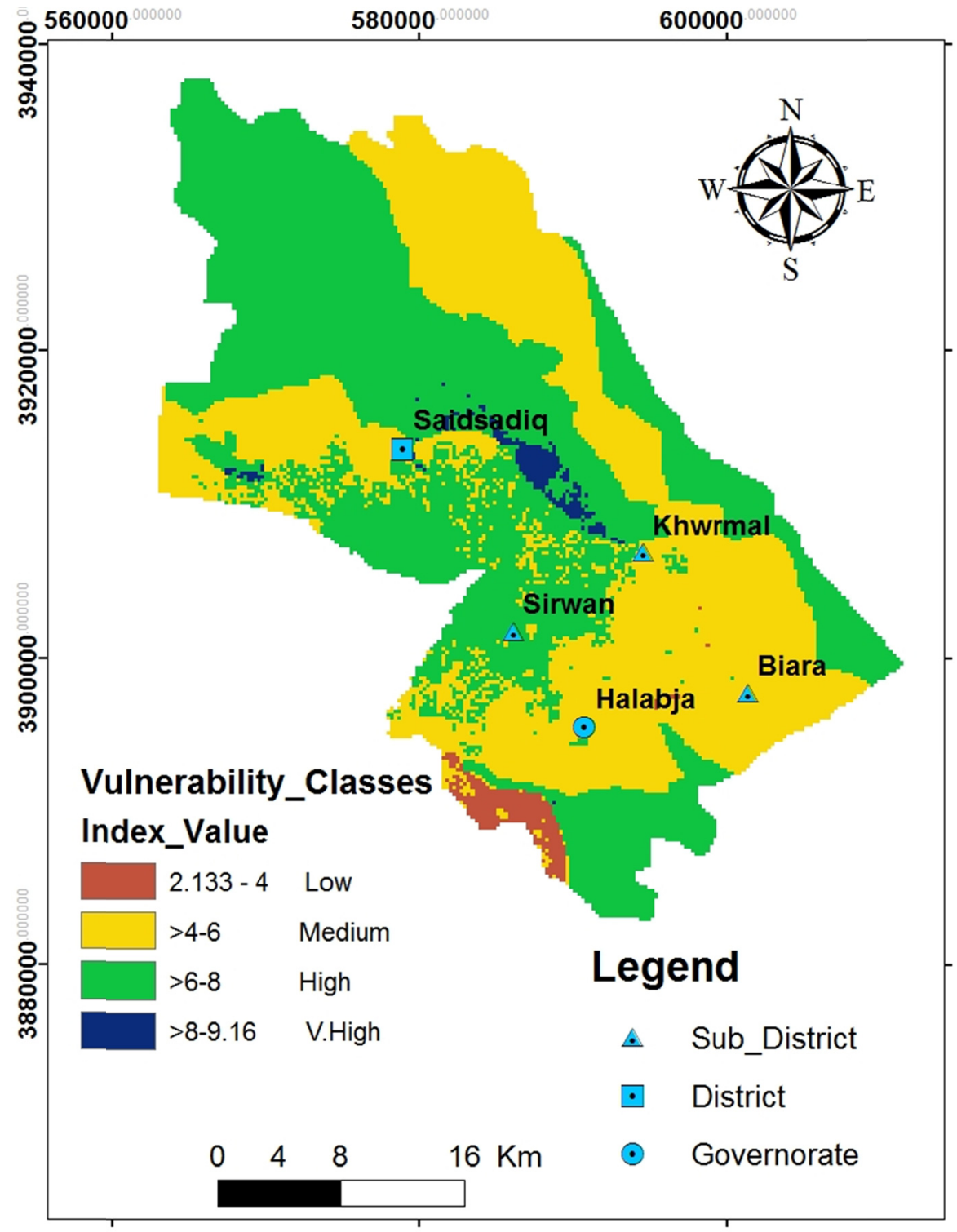

Fig. 4 VLDA vulnerability index map of HSB. 


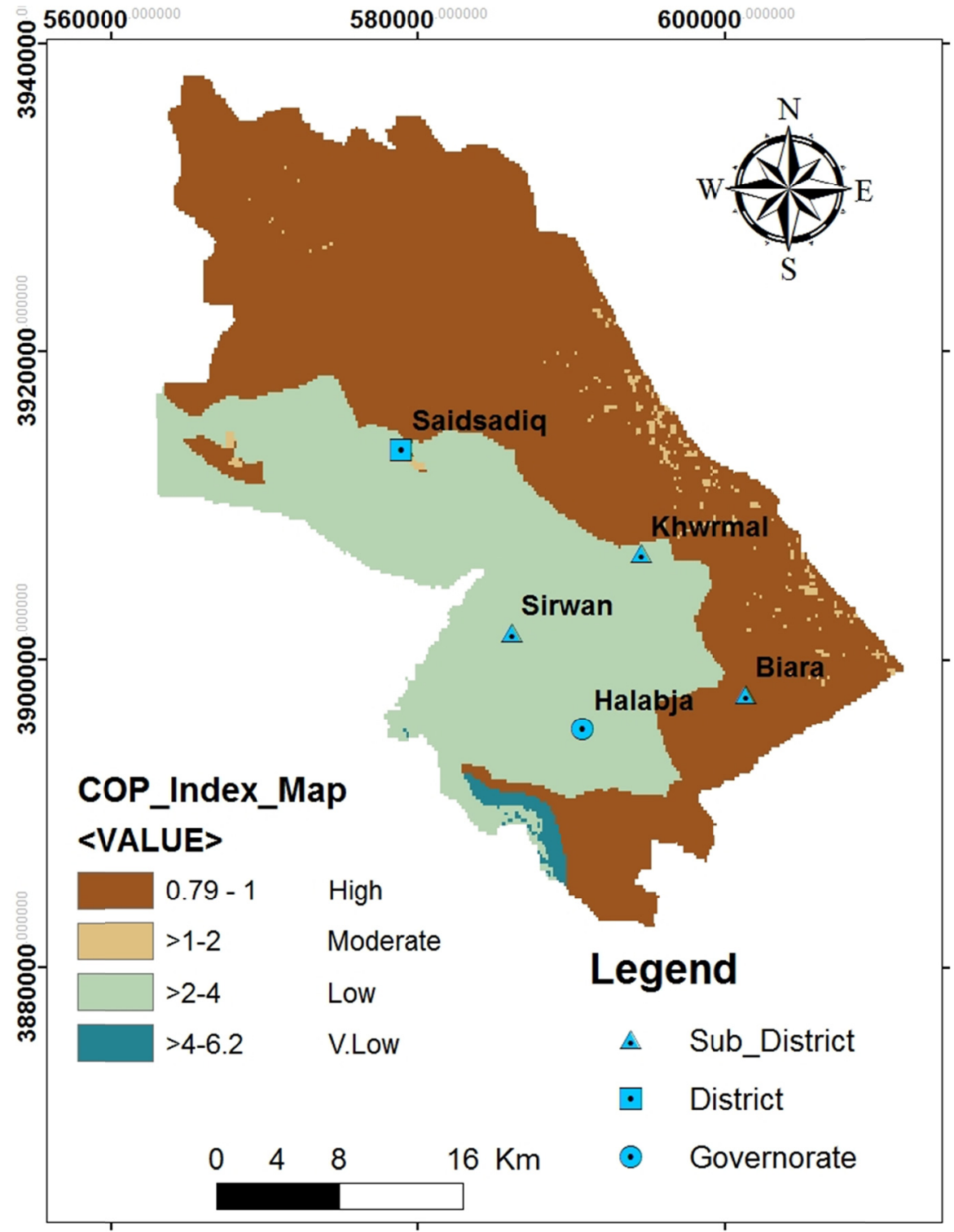

Fig. 5 COP vulnerability index map of HSB.

\section{Validation of the Result}

The vulnerability of groundwater to contamination was evaluated by comparing vulnerability index value with the age of groundwater. Regions of recent recharge are liable to contamination from surface waters. Various methods endure for evaluation dating from groundwater age. The method applied to estimate groundwater method in this study is the tritium (unstable isotopes). Tritium or ${ }^{3} \mathrm{H}$ is a radioactive isotope of hydrogen (through one proton and two neutrons) with a half-life of (12.4) year [15].
Concentrations of tritium are deliberate in $\mathrm{TU}$ (tritium units) where $1 \mathrm{TU}$ is described as the occurrence of one tritium in $10^{18}$ atoms of hydrogen (H). In the present study, tritium unstable isotope analyzed from one rain sample and twenty water well samples from different groundwater aquifers to find out the groundwater age. Rain sample had a tritium value of (4.8) TU and a mean value of groundwater samples were (4.28) TU for (CKFA, TKA, and JKA) aquifers and (2.28 and 3.03) TU for CFA and AIA aquifers, respectively (Table 5). 
There is no definite classification for age estimation based on tritium results. While, Mckenzie et al. [16], classified the age of groundwater samples by classifying water as being modern and pre-bomb. Tritium values of more than (0.3) TU are considered as modern water (i.e. recharge after 1965) and values smaller than or equal to $(0.3) \mathrm{TU}$ to considered to be pre-bomb spikes to recharge (i.e. recharge before 1965). While [13] classified groundwater age as follows:

- $<0.8$ TU assigns sub-modern water (prior to 1950s);

- 0.8 to 5 TU assigns a mix of sub-modern and modern water.

- $>5$ to 15 TU assigns modern water $(<5$ to 10 years);

- >15 to 30 TU assigns some bomb tritium;

- >30 TU assigns recharge generate in the 1960 s to 1970s.

Referring to both classifications, the tritium value, Table 2 designates that the groundwater in the HSB is modern or a mix of sub-modern and modern water. The tritium data present approaching as to the mean residence time of "old" versus "new" groundwater in the HSB. The essential hypothesis for using groundwater age to set up vulnerability is that groundwater with a fairly rapid vertical transport rate has a younger age. Since most contaminants exist near the earth's surface, younger groundwater is, therefore, more vulnerable.

The results of tritium analysis exposed that groundwater in the (CKFA, TKA and JKA) aquifers is younger than in both (AIA and CFA), furthermore, groundwater in the (AIA) aquifer is younger than (CFA) as tritium value of AIA is higher than in CFA (Fig. 4). Based on this classification, groundwater vulnerability was assessed by comparing to the tritium $\left({ }^{3} \mathrm{H}\right)$ value and groundwater age. This approach scrutinizes the comparison with a spatial pattern of variability of these maps along with a common cross-section A-B (Fig. 6), to observe the linear relationship between vulnerability index value and groundwater tritium value. The results show a better match between the patterns of the tritium value of groundwater and vulnerability index value

Table 2 Results of tritium analysis of groundwater samples in the HSB.

\begin{tabular}{|c|c|c|c|c|c|}
\hline Sample code & Site & $3 \mathrm{H}$ & & Average $3 \mathrm{H}$ & Aquifer \\
\hline ITB & Banishar Mosques Well & 4.7 & \pm 0.3 & \multirow{8}{*}{4.28} & \multirow{8}{*}{$\begin{array}{l}\text { CKFA. } \\
\text { TKA and JKA }\end{array}$} \\
\hline ITB2 & Basak Well & 3.8 & \pm 0.3 & & \\
\hline ITJ & Jalela Village Well & 4 & \pm 0.3 & & \\
\hline ITS1 & Saraw Swbhan Agha & 4.5 & \pm 0.3 & & \\
\hline ITM & Mzgawta & 4 & \pm 0.3 & & \\
\hline ITSb & SheraBara & 4.3 & \pm 0.3 & & \\
\hline ITT2 & Tawanawal & 4.6 & \pm 0.3 & & \\
\hline ITD & Darbarulla & 4.3 & \pm 0.3 & & \\
\hline ITTh & Halabaj Taymwr Hassan & 3.3 & \pm 0.3 & \multirow{8}{*}{3.03} & \multirow{9}{*}{ AIA } \\
\hline ITS & Sirwan & 2.3 & \pm 0.3 & & \\
\hline ITSs & Shekhan Shanadactry Road Project & 3.1 & \pm 0.3 & & \\
\hline ITSm & Soila Mesh & 3 & \pm 0.3 & & \\
\hline ITGs & Gulajoy Saroo & 3.2 & \pm 0.3 & & \\
\hline ITMh & Mstakani Haji Ahmad & 3 & \pm 0.3 & & \\
\hline ITT & Taza De & 3 & \pm 0.3 & & \\
\hline ITB3 & Bezhawa & 3.3 & \pm 0.3 & & \\
\hline ITX & Kharpane Well & 2.4 & \pm 0.3 & \multirow{4}{*}{2.28} & \\
\hline ITBk & Balkhay Khwaroo & 2.3 & \pm 0.3 & & \multirow{3}{*}{ CFA } \\
\hline ITS2 & Sargat & 2.1 & \pm 0.3 & & \\
\hline ITBb & Bani Bnok & 2.3 & \pm 0.3 & & \\
\hline
\end{tabular}



Saidsadiq Basin, Iraq

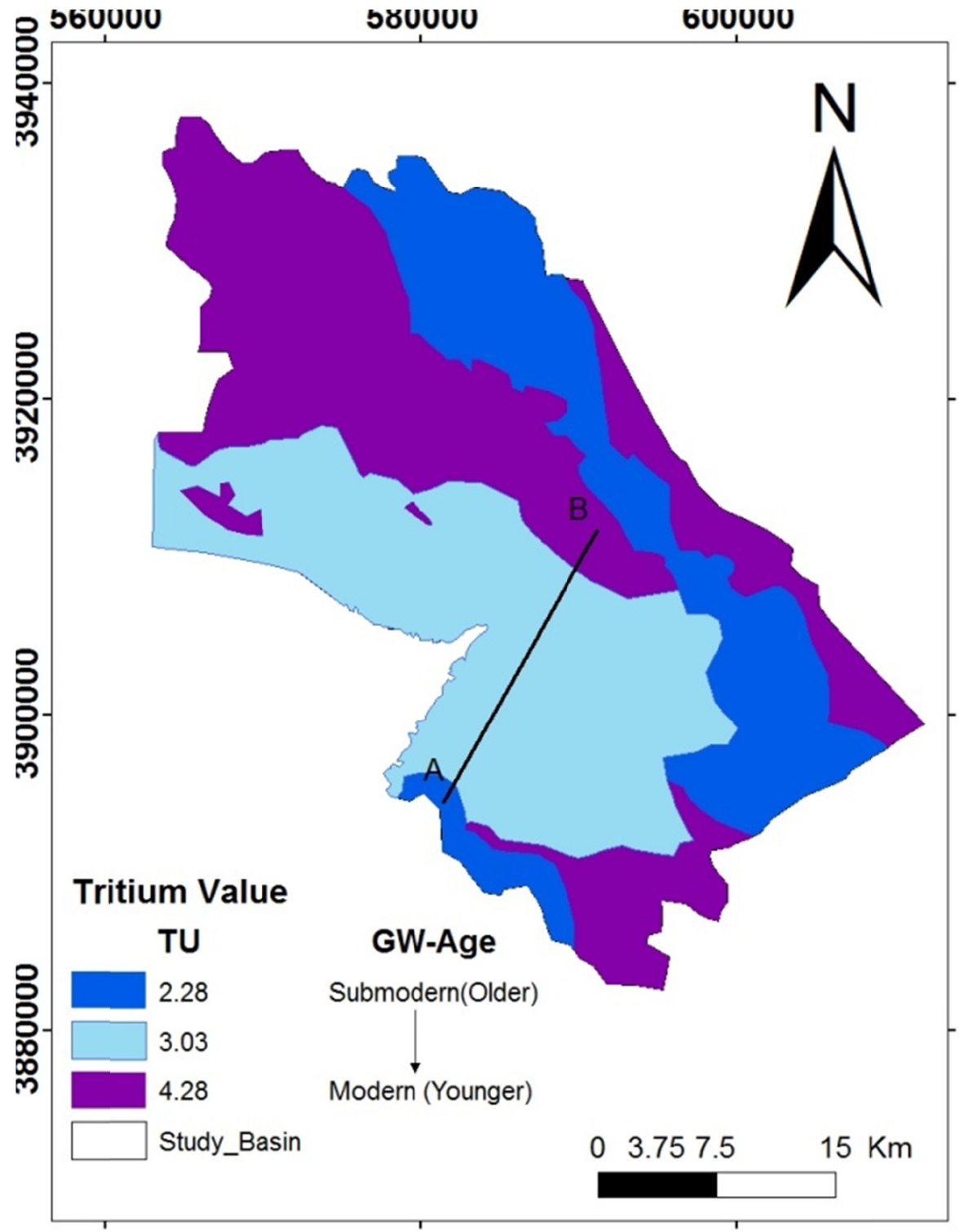

Fig. 6 Groundwater age and tritium value of aquifers at the HSB. 

Saidsadiq Basin, Iraq

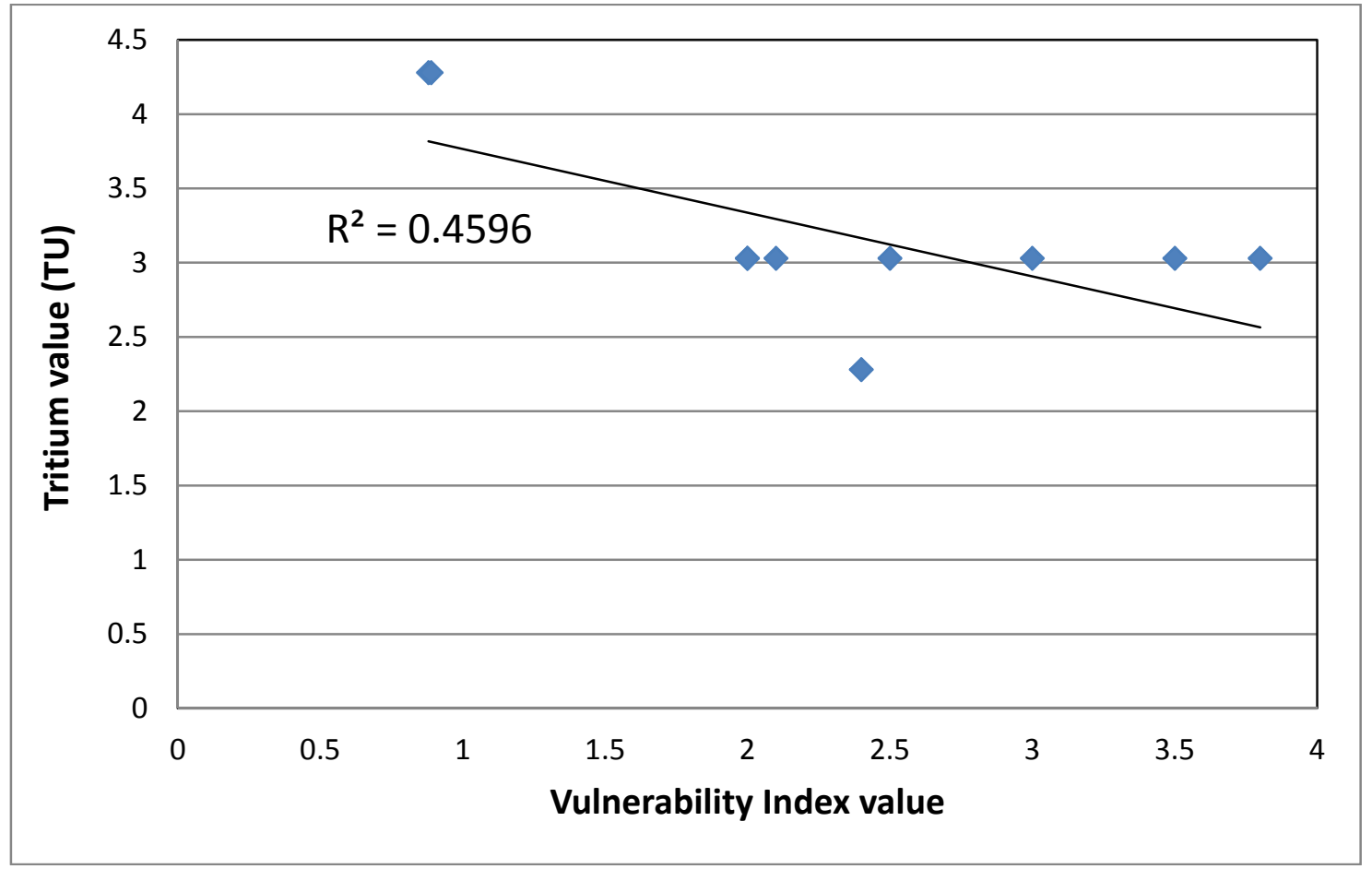

Fig. 7 Regression between COP model vs. tritium value for cross-section A-B.

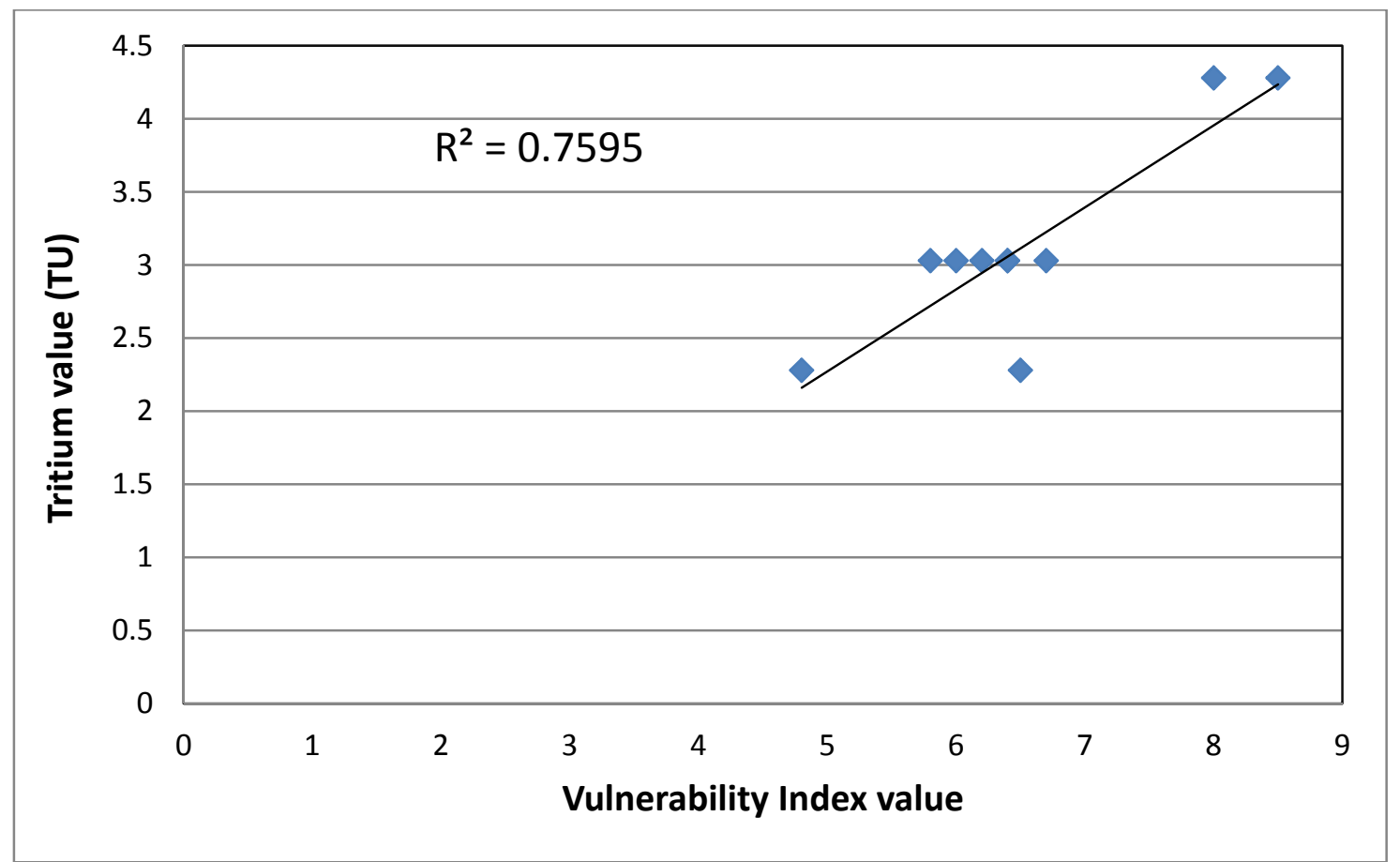

Fig. 8 Regression between VLDA model vs. tritium value for cross-section A-B.

achieved from VLDA method compared to the COP model (Figs. 7 and 8). Therefore based on this verification, it can be concluded that the VLDA vulnerability model reflects the real vulnerability situation in the HSB.

\section{Conclusion}

Two different models specifically COP and VLDA have been applied to assess the possible groundwater vulnerability to pollution for the HSB. The value of 
the VLDA indexes ranged from 2.133-9.16, and the value of the COP indexes ranged from 0.79-6.2. The elevated index value of the VLDA models refers to the higher class of vulnerability, whilst the value of the lesser index value of the COP model refers to the higher rate of vulnerability.

COP model comprises (very low to high), while VLDA model embraces (low to very high) vulnerability classes. The remarkable disparity has been achieved from both applied models, therefore the outcome desirable to be validated. A ground-water age was applied to assess the vulnerability of groundwater to contamination. Areas of recent recharge are vulnerable to contamination from surface recharges. Rain water sample had a tritium value of $4.8 \mathrm{TU}$ and a mean value of groundwater samples was $4.28 \mathrm{TU}$ for CKFA, TKA, and JKA aquifers and 2.28 and $3.03 \mathrm{TU}$ for CFA and AIA aquifers respectively. This approach examines the relationship between the spatial distribution of variability index value and groundwater age. The results show a better match between the patterns of the tritium value of groundwater and the vulnerability index values achieved from VLADA model rather than COP model, because $R^{2}$ value achieved from this relation by applying VLDA model is about 0.75 while for COP model is about 0.45 , the closer of the value of $R$-squared on the graph to 1.0 , confirm the better the fit of the regression line. This validation confirmed that the VLDA vulnerability model reflects the real vulnerability situation in the HSB compared to the COP model.

\section{References}

[1] Mendoza, J. A., and Barmen, G. 2006. “Assessment of Groundwater Vulnerability in the Rio Artiguas Basin, Nicaragua." Environmental Geology 50: 569-80.

[2] Attoui, B., Kherci, N., and Bousnoubra, H. 2012. "State of Vulnerability to Pollution of the Big Reservoirs of Groundwater in the Region of Annaba-Bouteldja (NE Algeria)." Geographia Technica 2: 1-13.

[3] Ali, S. S. 2007. "Geology and Hydrogeology of Sharazoor-Piramagroon Basin in Sulaimani Area,
Northeastern Iraq." Unpublished Ph.D. thesis, Faculty of Mining and Geology, University of Belgrade, Serbia.

[4] Statistical Directorate in Sulaimaniyah. 2014. "Population of Halabja Saidsadiq Cities." Archive Department.

[5] Abdullah, T. O., Ali, S. S., Al-Ansari, N. A., and Knutsson, S. 2015a. "Effect of Agricultural Activities on Groundwater Vulnerability: Case Study of Halabja Saidsadiq Basin, Iraq.” Journal of Environmental Hydrology 23 (10): 1-20.

[6] Abdullah, T. O., Ali, S. S., Al-Ansari, N. A., and Knutsson, S. 2015b. "Vulnerability of Groundwater to Pollution Using Three Different Models in Halabja Saidsadiq Basin, Iraq.” European Water 57: 353-9.

[7] Jassim, S. Z., and Guff, J. C. 2006. "Geology of Iraq.” In D. G. Geo Survey, edited by Jassim, S. Z. Min. Invest. Publication, 340.

[8] Buday, T., and Jassim, S. 1987. "The Regional Geology of Iraq: Tectonis, Magmatism, and Metamorphism." In Stratigraphy, edited by Kassab, I. I., and Abbas, M. J. Baghdad: State Establishment of Geological Survey and Minieral Investigations, 445.

[9] Zhou, J., Lim Q., Guo, Y., Guo, X., Li, X., Zhoa, Y., and Jia, R. 2012. "VLDA Model and Its Application in Assessing Phreatic Groundwater Vulnerability: A Case Study of Phreatic Groundwater in the Plain Area of Yanji County, Xinjiang, China.” Environmental Earth Science Journal 67: 1789-99.

[10] Abdullah, T. O., Ali, S. S., Al-Ansari, N. A., and Knutsson, S. 2016a. "Assessing the Vulnerability of Groundwater to Pollution Using DRASTIC and VLDA Models in Halabja Saidsadiq Basin, NE-Iraq.” Journal of Civil Engineering and Architecture 10: 1144-59. doi: 10.17265/1934-7359/2016.10.006.

[11] Abdullah, T. O., Ali, S. S., Al-Ansari, N. A., and Knutsson, S. 2016b. "Groundwater Vulnerability Using DRASTIC and COP Models: Case Study of Halabja Saidsadiq Basin, Iraq." Engineering 8: 741-60. http://www.scirp.org/journal/PaperInformation.aspx?Pape $\mathrm{rID}=71681$.

[12] Daly, D., Dassargues, A., Drew, D., Dunne, S., Goldscheider, N., Neale, S., Popescu, C., and Zwhalen, F. 2002. 'Main Concepts of the 'European Approach' for (Karst) Groundwater Vulnerability Assessment and Mapping." Hydrogeol J 10 (2): 340-5.

[13] Goldscheider, N., and Popescu, C. 2004. "The European Approach." In Vulnerability and Risk Mapping for the Protection of Carbonate (Karst) Aquifers, edited by Zwahlen, F. Brussels: European Commission, 17-21.

[14] Vias, J. M., Andreo, B., Perles, M. J., Carrasco, I., Vadillo, P., and Jim'enez, P. 2006. "Proposed Method for Groundwater Vulnerability Mapping in Carbonate (Karstic) Aquifers: The COP Method. Application in 

Saidsadiq Basin, Iraq

Two Pilot Sites in Southern Spain." Hydrogeology Journal 14: 912-25. doi: 10.1007/s10040-006-0023-6.

[15] Kumar, P. R., and Somashekar, R. K. 2011. "Environmental Tritium and Hydrochemical Investigations to Evaluate Groundwater in Varahi and Markandeya River Basins, Karnataka, India.” Journal of
Environmental Radioactivity 102: 153-62.

[16] Mckenzie, J. M., Mark, B. G., Thompson, L. G., Schotterer, U., and Lin, P.-N. 2010. "A Hydrogeochemical Survey of Kilimanjaro (Tanzania): Implications for Water Sources and Ages." Hydrogeology Journal 18: 985-95. 